TEMAS EMERGENTES

\title{
La teoría de la acción situacional de la causación del delito y sus posibilidades explicativas de una problemática latinoamericana
}

\author{
The Situational Action Theory of Crime and its explanatory possibilities \\ of a Latin American problem
}

\author{
Clarissa Pepe Ferreira (iD \\ Universidad de São Paulo, Brasil
}

\begin{abstract}
RESUMEN Este estudio corresponde a un primer acercamiento analítico entre una teoría criminológica contemporánea y una problemática latinoamericana en concreto, con vistas a verificar posibilidades explicativas. Se ha empleado la teoría de la acción situacional de la causación del delito (TASCD), de Per-Olof H. Wikström, al análisis de la participación de adolescentes y jóvenes en el narcotráfico. Para ello, han sido utilizados como objeto de estudio algunos trabajos de campo ejecutados con anterioridad en favelas de la ciudad de Río de Janeiro, Brasil. Se verificó un potencial de diálogo fructífero entre ambos, tanto en lo concerniente a observar elementos de la teoría en estudios empíricos, como en lo que respecta a dar pasos adelante en la comprensión del fenómeno criminológico evaluado.
\end{abstract}

PALABRAS CLAVE Conflicto social, criminología, delincuencia juvenil, tráfico de estupefacientes, violencia.

ABSTRACT This study has carried out a first analytical approach between a contemporary criminological theory and a specific Latin American problem, to verify explanatory possibilities. Per-Olof H. Wikström's Situational Action Theory of Crime (TASCD) was used to analyze the participation of adolescents and young people in drug trafficking. Some previous field work carried out in the favelas of the city of Rio de Janeiro, Brazil, was used as the object of study. A fruitful dialogue was verified, both regarding the confirmation of the theory and regarding taking a few steps further in understanding the criminological phenomenon evaluated.

KEYWORDS Criminology, drug traffic, juvenile delinquency, social conflict, violence. 


\section{Introducción}

\section{La propuesta de trabajo}

El presente estudio aplica los dictámenes de la teoría de la acción situacional de la causación del delito (TASCD), de Per-Olof H. Wikström, al análisis de algunos casos de implicación directa de menores y jóvenes que viven en favelas cariocas ${ }^{1}$ con las redes de narcotráfico presentes en la ciudad de Río de Janeiro, Brasil. Su objetivo específico es lograr un primer acercamiento entre dicha teoría criminológica contemporánea y el mencionado objeto de estudio, con vistas a verificar la posibilidad de diálogo entre ambos. Para ello, han sido examinadas algunas fuentes indirectas, en concreto, los resultados de cuatro estudios de campo elaborados por otros investigadores entre 1999 y 2009 con el mismo objeto de estudio aquí elegido. A título de inspiración metodológica, se buscó armar algo relativamente cercano a un metaanálisis, ${ }^{2}$ cuyo producto ha sido interpretado bajo lo propuesto por la TASCD.

Hay que señalar que los estudios que se están llevando a cabo en este momento con la TASCD están volcados hacia la producción de datos empíricos con empleo del método cuantitativo (Wikström y otros, 2012; Rodríguez y Birkbeck, 2017; Maíllo y Rojas, 2018). Lo que tratan de hacer es precisar la validez de la teoría siguiendo, básicamente, los siguientes pasos: crear un instrumento de medición, aplicar el test de hipótesis y verificar la capacidad de predicción de la teoría. Este trabajo, no obstante, se acerca a su fuente de datos de manera indirecta y emplea el método cualitativo. Lo que se va a ver en él no es técnicamente una comprobación de teoría, sino más bien la presentación de una teoría criminológica de reciente desarrollo y todavía poco conocida en Latinoamérica, conjugada con su proyección sobre un duro y peculiar rasgo de la realidad de dicho subcontinente, con vistas a tantear la potencialidad de dicha teoría y su posibilidad de alumbrar la comprensión más humanizada de un objeto de estudio muy particular.

1. El término favelas en Brasil sería lo equivalente a lo que en España se conoce como chabolas, villas miseria en Argentina, tugurios en Colombia o asentamientos irregulares en México. En cuanto al término carioca, se refiere a todo aquél o aquello que es nativo de la ciudad de Río de Janeiro.

2. Técnicamente, el metaanálisis es «un procedimiento sofisticado de extraer conclusiones generales de todos los estudios previos sobre una determinada cuestión, o sea, estudiar cuál es el cuadro que aparece tras analizar conjuntamente todos los estudios previos» (Maíllo, 2009: 404). En el presente trabajo, sin embargo, sólo se van a examinar cuatro estudios hechos con anterioridad sobre delincuencia juvenil y narcotráfico en la ciudad de Río de Janeiro. Sería, por lo tanto, una imprecisión considerarlo un metaanálisis. No obstante, se ha tomado la libertad de inspirarse en ello para poder guiar el trabajo rumbo a la construcción de un primer acercamiento no sólo hacia una teoría de elaboración reciente, sino entre ella y una problemática social muy particular. 


\section{La elección de la TASCD}

Muchas son las teorías y enfoques criminológicos que, desde el paradigma sociológico, se podría haber seleccionado como referencial de análisis de la problemática en cuestión. La opción por la TASCD no significa que se ve en ella superioridad frente a lo demás. Estriba en acercarse a una teoría criminológica contemporánea, aprovechando los elementos que se nos ofrece para reflexionar sobre un fenómeno social bastante complejo. Se trata de intentar lanzar luces nuevas sobre la indagación de por qué, entre personas sometidas a las mismas condiciones sociales, culturales, económicas, etcétera, hay adolescentes y jóvenes que son seducidos y reclutados por la violencia armada organizada alrededor del tráfico de drogas, mientras que otros no lo son.

La TASCD puede posibilitar al debate criminológico un alejamiento de la tradicional polarización entre libre albedrío y determinismo social. Maíllo (2009: 555) considera que «desde mediados de la década de 1990 se había producido cierto estancamiento en la teoría criminológica [...] tendencia que ha sido rota con decisión por la teoría de la acción situacional». El propio Wikström (2006) apunta que la ausencia de una teoría de la acción, una insuficiente integración de los niveles de explicación, una definición poco clara del delito y una frecuente confusión entre correlación y causación - el mezclar síntomas con explicaciones- son problemas que han dificultado la presentación de explicaciones del delito plausibles. Todo ello, según el autor, ha obstruido la ejecución de investigaciones sólidas, que pudieran indicar unas políticas de prevención y control del delito realmente prometedoras, capaces de aunar la teoría criminológica con una política criminal eficaz.

La TASCD pretende ofrecer soluciones a los problemas mencionados. Esta teoría postula que los individuos en general llevan a cabo sus acciones según como suelen tomar sus decisiones y como ven las alternativas que tienen a su disposición. Así, busca comprender y explicar los mecanismos situacionales que operan conectando el individuo con el escenario del delito, introduciendo el hábito en el debate criminológico sobre las elecciones humanas e integrando tales mecanismos con los de tipo social y transformativo (Maíllo, 2009; Wikström, 2006).

Por otra parte, se ha identificado que son aún muy escasas las investigaciones sobre la TASCD a nivel internacional. Una búsqueda en la base de datos Web of Science con las claves «situational action theory» $\mathrm{y}$ «Wikström» ha presentado solamente 11 resultados repartidos entre Norteamérica (Estados Unidos y Canadá) y Europa (Alemania, Inglaterra, Austria, Bélgica y Suecia), y ninguna publicación en el ámbito iberoamericano. En la base de datos Google Scholar, con las mismas claves — redactadas en castellano- y seleccionando sólo resultados en el idioma español, la búsqueda ha regresado 31 resultados, entre los cuales predomina la producción científica de España; lo mismo se hizo en portugués y se obtuvo como resultado 18 trabajos acadé- 
micos, la gran mayoría proveniente de Portugal. En suma, en América Latina apenas se han visto estudios empleando la TASCD. El presente trabajo, por lo tanto, tiene la importancia de ayudar a llenar este vacío.

\section{La elección del objeto de estudio}

El escenario de ajustes de cuentas y enfrentamientos armados no es una particularidad del narcotráfico carioca, todo lo contrario. Se ha visto materializarse una y otra vez, desde hace tiempo, en diversos países latinoamericanos (Borba, 2009). Uno de los nombres más potentes de la criminología crítica, el italiano Alessandro Baratta, ha comentado que Río de Janeiro «es la representación concentrada de la historia del capitalismo brasileño [y que] Brasil es, a su vez, la representación de la historia del capitalismo occidental» (Baratta, 2003: 22; traducción propia):

Los veinte años de criminalización de jóvenes pobres en Río de Janeiro por tráfico de drogas al por menor son al mismo tiempo una historia reciente y una historia antigua. Como historia antigua, empieza con la abolición de la esclavitud y con el proceso de urbanización, cuando las ciudades ganaran un nuevo perfil, con la remoción de los barrios pobres del centro hacia la periferia. Las grandes obras de modernización asumieron el significado de operaciones de higiene social, explicitando bien el «miedo blanco» y el proyecto de exclusión y de marginalización de los libertados, la representación burguesa de lo que sería la ciudadanía negativa de las clases subalternas. La elección de Río para ilustrar esta historia antigua es una acertada elección, porque Río es un espejo fidedigno que refleja, de manera aumentada, lo que sucedió en el resto de Brasil. También es una acertada elección para ilustrar la historia reciente de este país, ya que en Río se puede observar, mejor que en cualquier otra ciudad brasileña, el desplazamiento de la ideología de la seguridad nacional de la época de la dictadura militar a la ideología de la seguridad urbana de los días actuales (Baratta, 2003: 22; traducción propia).

Según Baratta, el hecho de que Brasil haya sido el último país del globo en acabar con la esclavitud, así como el hecho de ser - y no por casualidad - uno de los países con mayores desigualdades sociales a nivel internacional, en su opinión hizo que: i) «la sociedad brasileña ostente, de manera directa y elemental, las contradicciones de la sociedad capitalista en general»; ii) «la dependencia recíproca entre desigualdad y violencia, entre exclusión social y selectividad del sistema represivo se presenten en Brasil, por así decirlo, en estado puro» (Baratta, 2003: 22; traducción propia).

Dowdney, tras una intensa investigación participante en una favela carioca en la que estuvo viviendo largo tiempo, informó que el «comercio de drogas al por menor en Río de Janeiro involucra una organización paramilitar a nivel local, la dominación territorial y casi política de espacios geográficos controlados por facciones de narcotraficantes por medio de un sistema de "reciprocidad forzada"» (Dowdney, 2003: 
197; traducción propia). Registró la existencia de por lo menos 10.00o combatientes armados trabajando para estas facciones - adolescentes y jóvenes incluidos-, haciendo uso de armas de guerra y contribuyendo a que los niveles de violencia y las tasas de asesinatos registrados en Río llegaran a superar los índices de muertes de civiles y combatientes en muchos conflictos armados importantes de nuestro tiempo.

Hasta el año 2011, Brasil ocupaba la sexta posición en el ranking internacional de homicidios juveniles (Waiselfisz, 2011) y presentaba una proporción de 52,9 homicidios juveniles por cada 100.000 habitantes. Para dimensionar mejor la gravedad del problema brasileño: en el mismo periodo, España ocupaba la 62. ${ }^{\text {a }}$ posición en dicho ranking y tenía una proporción de 1,1 homicidios juveniles por cada 100.00o habitantes. Considerando que el promedio de edad de un brasileño era de 29 años en aquel momento, y que en Europa ese factor equivalía a 40 años (Naciones Unidas, 2010), la cuestión toma proporciones aún más alarmantes.

Los asesinatos fueron la principal causa de óbitos entre adolescentes y jóvenes en Brasil en 2017. Fueron registrados en aquel año un récord de 69,9 homicidios por cada 100.000 jóvenes brasileños. En Río de Janeiro, la proporción para el periodo fue de 92,6 homicidios juveniles por grupo de 100.000. Las muertes violentas intencionales que victimizan el colectivo infantojuvenil en el país suelen ser provocadas por enfrentamientos con la policía, con el crimen organizado — narcotráfico, básicamente - y entre pares, es decir, adolescentes y jóvenes con perfil semejante conviviendo en contextos sociales parecidos (Pérez, 2011). Cabe informar, además, que cada asesinato de un individuo no negro contabilizado en Brasil en 2017 correspondió a aproximadamente tres asesinatos de personas negras (IPEA, 2019).

\section{Revisión de la literatura}

\section{Situando la TASCD en términos criminológicos}

La TASCD es una teoría contemporánea y corresponde a un modelo criminológico de teorías integradas, que, acorde con Maíllo (2009: 531-559), tratan de «tomar de cada teoría aquellas partes que resulten más prometedoras y tratar de formar una nueva teoría con todas ellas». Forma parte de un movimiento titulado "criminología integrativa», que se caracteriza por un abordaje interdisciplinario del fenómeno delictivo, incluyendo diversas teorías criminológicas y otros cuerpos de conocimientos con el objetivo de «abarcar todos y cada uno de los métodos, teorías y datos que sirvan para arrojar luz sobre la producción del delito, los delincuentes y el control social» (Gregg Barak, citado en Mclaughlin y Muncie, 2012: 117). Se parte del supuesto de que el estudio de la etiología del delito y los estudios relacionados a la regulación y prevención de los comportamientos delictivos se encuentran necesariamente vinculados entre sí y con los análisis multidisciplinarios (Mclaughlin y Muncie, 2012: 117-119). 


\section{«Personas, entornos y actos delictivos: Los mecanismos de situación} y la explicación del delito»

El título de este apartado corresponde al del artículo de Wikström (2006: 509-551) que presenta y explica la TASCD a la comunidad científica hispanohablante. El autor empieza afirmando que sin una concepción clara de qué es el delito, qué es lo que mueve las personas a cometer actos delictivos (teoría de la acción), bien como de qué modo las características y experiencias individuales y las características del entorno interactúan en este proceso (integración de los niveles de explicación), no es posible trabajar en forma adecuada las causas del delito, ni tampoco comprender qué función tiene la articulación de los factores de desarrollo y cambio individuales con los factores sistémicos y sus cambios con el paso del tiempo en la explicación del delito.

Dicho eso, el autor pasa a la definición de qué es el delito: son actos de incumplimiento o infracción de normas morales definidas por la ley penal de una determinada sociedad en un determinado momento histórico, que difieren de las demás normas morales por la mayor formalidad con que son generadas (poder legislativo), ejecutadas (poder ejecutivo) y sancionadas (poder judiciario). Con ese concepto, según el autor, a diferencia de los de «conducta antisocial», «desórdenes de conducta»y «delincuencia», se consigue poner el énfasis en la infracción normativa, por lo que es preferible por ser más preciso. Es justo la precisión de este concepto lo que le permite explicar cualquier tipo de delito, incluso cuando cambia el rol de actos delictivos definidos socialmente, lo que posibilita el desarrollo de una teoría general. Asimismo, es posible considerar que el desplazamiento del punto de análisis del acto del individuo hacia la infracción normativa favorece la evasión de la incidencia en el problema criminológico del etiquetamiento.

En seguida, el autor pasa al análisis de qué mueve a las personas a infringir las normas morales definidas por la ley. En este sentido, propone que las personas son movidas a la acción -incluyendo en ello los actos delictivos- por el modo en que contemplan sus alternativas de acción y toman sus elecciones cuando afrontan las particularidades de un determinado entorno. Según Wikström, éste es el argumento fundamental de la TASCD.

A raíz de ello, sostiene que la relación recíproca entre propensiones al delito e inducciones al delito construyen «mecanismos de situación» que elucidan la integración de los niveles individual y social que componen necesariamente la explicación del delito. Se debe entender por propensiones al delito los conocimientos, aptitudes, experiencias y la moralidad del sujeto, y por inducciones al delito, las oportunidades y fricciones, el contexto moral en que está inmerso el sujeto, es decir, las características del entorno en general. La relación d constante diálogo de estos dos elementos influirá en si una persona tiende a ver el delito como una alternativa y tienda a actuar en este sentido bajo determinadas circunstancias específicas. Es a este proceso que 
Wikström se refiere cuando habla de «mecanismos de situación», que es en concreto lo que vincula la persona al entorno y al acto delictivo.

Es menester destacar que Wikström se opone al enfoque de los factores de riesgo presentes en las teorías criminológicas tradicionales (Maíllo, 2009: 555). Eso se debe a que su teoría no considera que la causación del delito sea determinada directamente o por factores sistémicos (características de la estructura y organización social, como por ejemplo la desigualdad, la segregación y las normas sociales y morales) o bien por factores individuales (padrones de desarrollo y cambio individual), sino que es resultado de los mecanismos de situación. Dichos factores, eso sí, tienen un importante papel en la comprensión de la causación del delito, pero su incidencia en ello es indirecta, razón por la cual Wikström les ha nombrado «causas de las causas»:

Dicho sin rodeos, demostrar la correlación y realizar predicciones puede (en la mayoría de los casos) no ser un conocimiento muy útil si no existe una causación subyacente. [...] Existen, por así decirlo, demasiadas causas potenciales (correlatos, predicciones) de las que nos esforzamos por extraer un sentido. [...] Confundir correlación y causación puede llevar a decisiones de política totalmente incorrectas. [...] Sostengo que, para avanzar en el conocimiento sobre la causación del delito, debemos movernos desde el centramiento actual en la planificación de patrones no aleatorios de correlación y la realización de predicciones (enfoque de factor de riesgo), al hecho de concentrarse en la tarea de establecer la causación y proporcionar una explicación (enfoque de explicación). [...] Esto no significa que establecer correlaciones y realizar predicciones no sean actividades importantes. Por el contrario, son puntos de partida importantes en la búsqueda de la causación y la explicación. Asimismo, no se trata de alegar que en criminología no se consideran la causación y la explicación, simplemente se centra fundamentalmente en demostrar la correlación y realizar predicciones (Wikström, 2006: 514-515).

El autor asevera que las acciones o inacciones intencionales de un sujeto no pueden nunca ser explicadas tan sólo por las condiciones del entorno ni tampoco en forma exclusiva por las características (genéticas o adquiridas) y experiencias individuales, por dos razones:

- Porque la «lectura» que el sujeto hace de su campo de actuación está filtrada por sus características y experiencias individuales.

- Porque las motivaciones individuales, la percepción de las alternativas de acción y el cumplimiento de elecciones son consecuencia del modo que tiene el sujeto de tratar con su entorno ( «las acciones nunca se efectúan en un vacío de entorno» (Wikström, 2006: 534).

La teoría de Wikström tiene como telón de fondo la teoría clásica de la acción, la cual, en resumidas cuentas, propugna que cuando una persona siente el deseo por 
hacer algo, cree que puede satisfacerlo, tiene despertada su intención por hacerlo y actúa según esta intención, obtendrá los resultados deseados si no sucede ninguna interferencia que cambie el curso de la acción o los resultados pretendidos. De este modo, la causa de la acción, en conformidad con la teoría clásica de la acción, es la motivación producida por creencias y deseos. Sin embargo, el autor, reflexionando sobre los elementos clave de la teoría clásica de la acción, hace las siguientes aclaraciones y proposiciones:

Primero, las creencias, que pueden ser verdaderas o falsas, tienen que ver con las consideraciones sobre si el deseo puede o no ser satisfecho.

Segundo, la motivación no puede ser explicada apenas por la pareja deseo-creencia. Los deseos y las creencias forman parte de la tentación, algo que está conectado al placer y que por sí sólo no genera la acción. La oportunidad tiene aquí un papel fundamental, puesto que «una tentación puede definirse como una oportunidad percibida de satisfacer algún deseo en particular» (Wikström, 2006: 531). Pero es imprescindible dilucidar que «los deseos no causan motivación, ni tampoco lo hacen las oportunidades, pero su interacción sí lo hace» (Wikström, 2006: 532).

Tercero, existen razones para la acción que son independientes del deseo y de la obtención de placer, en que lo único que se quiere es llevar a cabo la acción porque se entiende que hay que hacerlo, más allá de si eso le complacerá a uno o no. A eso se nombra compromiso. La oportunidad aquí igualmente tiene un papel fundamental.

Cuarto, la percepción - muy poco trabajada por la teoría clásica de la acción y la teoría de la adopción de decisiones - es, acorde con el autor, lo que arroja luz «a la cuestión de por qué las personas aprecian ciertas alternativas de acción en primer lugar (y no aprecian otras)» (Wikström, 2006: 525). Para Wikström, la percepción es la frontera entre las alternativas de acción que el sujeto puede identificar y el tipo de elecciones que podrá hacer a raíz de ello. En concreto, «la percepción es la información que obtenemos de nuestros sentidos (por ejemplo, ver, oír, y sentir) y nuestra interpretación basada en conocimientos y experiencias, y evaluación moral de la mencionada información» (Wikström, 2006: 525). La percepción es lo que vincula la persona a su entorno.

Quinto, las provocaciones consisten en una reacción emocional negativa (ira, enfado, furia, por ejemplo) dirigida contra fricciones, o sea, intervenciones no deseadas de terceros u obstáculos externos, que afectan (o pueden afectar) la esfera autodefinida de influencia del sujeto:

Una provocación puede definirse como una inducción emocional a responder de un modo agresivo hacia la fuente percibida de fricción o hacia ese alguien o algo que representen la fuente de fricción. La agresión se define aquí como cualquier acción (inacción) llevada a cabo con la intención de dañar a otro ser humano o destruir un objeto. Una fuente percibida de fricción puede ser una persona o una entidad abs- 
tracta como «el Estado» $\mathrm{o}$ «los vecinos». El hecho de que una persona interprete una fuente de fricción como antagónica dependerá de sus conocimientos, experiencias y moralidad. La provocación es un concepto situacional porque las provocaciones son el resultado (interpretación de una intención antagónica) de la interacción entre la persona (sus conocimientos, experiencias y moralidad) y el entorno (el hecho de afrontar una fricción). (Wikström, 2006: 532).

Sexto, la motivación, pues, está compuesta por tentaciones, compromisos y provocaciones, y todos estos elementos poseen dimensiones morales y situacionales. Ésta es, para Wikström, la mejor forma de concebir las motivaciones. Pensar en motivaciones particulares para cada acto delictivo específico es un error, según el autor, puesto que el mismo acto delictivo puede ser cometido por diferentes razones.

Séptimo, los valores morales influyen en la evaluación que el individuo hace de las alternativas de acción, y tienen que ver con qué está bien o mal hacer - o no haceren circunstancias específicas:

El concepto de norma moral, tal y como se aplica aquí, no significa que una determinada norma moral tenga que ser juzgada como lo que está bien hacer (o no hacer), por algún criterio independiente (de orden superior) que indique lo que está bien y mal hacer (o no hacer) en una determinada circunstancia. Si una persona se atiene a una norma moral, cumple esta norma moral; si no lo hace, no la cumple. Una implicación obvia de lo anterior es que las personas pueden diferir en las acciones (e inacciones) que consideran que moralmente está bien o mal hacer (o no hacer) en una determinada circunstancia, con independencia de la norma moral. [...] No todas las acciones (inacciones) intencionales tienen una dimensión moral (es decir, una dimensión del bien y del mal). Sin embargo, creo que muchos (si no la mayoría) de los tipos de acciones (o inacciones) intencionales de cualquier importancia, al menos en determinadas circunstancias, la tienen. [...] Los actos que se realizan guiados por normas morales pueden denominarse acciones morales [...] Del mismo modo que las experiencias de éxito o fracaso y las consecuencias de las acciones (o inacciones) intencionales pueden dar lugar a cambios en las creencias de una persona (por ejemplo, puede ganar o perder confianza en su capacidad de lograr determinadas acciones o alcanzar una serie de metas), también pueden tener implicaciones respecto de los desarrollos y cambios en sus valores morales (por ejemplo, puede llegar a ver una serie de acciones o inacciones bajo una perspectiva moral diferente dependiendo de las consecuencias observadas de sus acciones o inacciones específicas) (Wikström, 2006: 521).

Octavo, el autor afirma sospechar que muchos actos delictivos son esencialmente causados por el hábito, más que por manifestaciones de elecciones deliberadas. Reflexionando sobre la existencia de dos sistemas básicos de procesamiento cognitivo —el sistema experiencial (asociativo) y el sistema racional (deliberativo)—, concluye que la acción no surge sólo de los procesos de elección que implican deliberación o 
razonamiento, sino que también se dan de modo muy espontáneo, de manera automática, sin la consideración de los pros y los contras, pero que son distintos de los simples reflejos porque son intencionales, tienen una dirección y unas condiciones de satisfacción. Ello son los hábitos: procesos guiados por un «seguimiento cognitivo mínimo o esporádico» (Wikström, 2006: 538), de percepción-elección rápido e irreflexivo, incluso enormemente inconsciente, que «tienden a repetirse a través de mecanismos asociativos» (Wikström, 2006: 538). A diferencia de las deliberaciones (orientación hacia el futuro, en respuesta a circunstancias nuevas, o sea, no familiares o no previstas, que exigen que el sujeto pare para pensar qué hacer), los hábitos se basan en experiencias pasadas de acciones o inacciones producidas en circunstancias familiares de entorno estable, que no implican nada nuevo o inesperado, y no exigen, por tanto, ningún tipo de evaluación o razonamiento. Cabe destacar, todavía, que un potente condicionante de los hábitos, para Wikström, es la obtención de éxito, repetidas veces durante largo periodo de tiempo, en el resultado de las acciones practicadas con anterioridad en entornos estables.

Por último, sobre los entornos (campos de actividad del individuo), el autor hace hincapié en que «es importante mantener en mente que los conocimientos y aptitudes, experiencias y moralidad actuales de una persona dependen de su modelo previo de interacciones con determinados entornos» (Wikström, 2006: 530).

Así las cosas, Wikström construye la TASCD a partir de los siguientes elementos: el compromiso moral, el contexto moral, la moralidad individual, las percepciones morales, los hábitos morales, los juicios morales, el autocontrol, la disuasión y las elecciones morales. El resultado de todo ello es una teoría criminológica con la estructura descrita a continuación, en palabras del propio autor:

Cuando una persona (con sus conocimientos y aptitudes, experiencias y moralidad) hace frente a un entorno (con sus oportunidades y fricciones específicas, y su contexto moral), esto puede: i) dar lugar a determinadas motivaciones (tentaciones, compromisos y provocaciones) y, ii) definir una serie de alternativas de acción y sus cualidades morales, para tratar estas motivaciones (percepciones morales). Sobre la base de las percepciones morales, una persona, bien: i) en virtud de un hábito (hábito moral) o ii) tras una cierta deliberación (juicio moral), forma una intención (realiza una elección moral). El hecho de que una elección moral se realice en virtud de un hábito moral o implique un juicio moral dependerá de la familiaridad del entorno y sus circunstancias. Los entornos y circunstancias familiares (y motivaciones coherentes) tenderán a favorecer a las elecciones basadas en un hábito moral, mientras que los entornos o circunstancias no familiares (y las motivaciones conflictivas) tenderán a favorecer a las elecciones basadas en juicios morales. Si la persona delibera sobre sus alternativas de acción (realiza un juicio moral), la libre voluntad, la elección racional y el autocontrol serán parte del proceso de elección; en otro caso, no lo serán (Wikström, 2006: 536). 
Una destacable aportación de la TASCD tiene que ver con su forma de abordar la moralidad individual, considerada como el grado hasta el cual los sujetos se sienten avergonzados o culpables por violar una determinada norma moral. La TASCD parte de la premisa de que los sujetos están propensos a variar a cualquier momento en sus valores morales y en el modo que les preocupa el cumplimiento de determinadas normas morales. En consecuencia, concluye que las personas tienen diferentes «umbrales morales», que cuanto más elevado sea más intensa tendrá que ser la inducción del entorno como para motivar al individuo a infringir una normal moral.

Otra importante aportación de la teoría de Wikström se refiere a las percepciones morales. La comprensión de que tanto mayor sea la correspondencia entre las normas morales individuales y las de los entornos en los que los sujetos participan, menor será la percepción de la infracción de las normas morales como una alternativa de acción, evidencia que el cumplimiento de las leyes no está relacionado a la elección del sujeto, sino a una etapa anterior del proceso de acción, es decir, la percepción de alternativas de acción (percepciones morales). Eso conduce a dos conclusiones: i) la disuasión (miedo a las consecuencias) no desempeña ningún papel a la hora de hacer que las personas cumplan las leyes; ii) el cumplimiento de la ley en estos casos no tiene que ver ni con las elecciones racionales ni tampoco con el ejercicio del autocontrol.

En cuanto a los hábitos morales, también se nota otra considerable contribución de la TASCD. Teniendo en cuenta una teoría de Epstein que predice que «cuanto más cargada emocionalmente esté una situación, más dominado estará el pensamiento de una persona por el sistema experiencial» (Wikström, 2006: 538), Wikström hace hincapié en la importancia de los hábitos morales, en especial porque entiende que gran parte del comportamiento humano está guiado por las experiencias personales de consecuencias pasadas de acciones o inacciones. Asimismo, el autor apunta dos cuestiones cruciales sobre los hábitos morales: i) las elecciones racionales, el miedo a las consecuencias (disuasión) y el autocontrol igual no desempeñan un papel contundente en el proceso de elección que da lugar a la acción o inacción, una vez que lo habitual no implica deliberación; ii) los hábitos morales y sus cambios pueden explicar las «entradas y salidas» del proceso de delincuencia persistente.

Sobre los juicios morales, definidos por el autor como la deliberación sobre las implicaciones morales relativas a actuar o no actuar y cuál la mejor manera de actuar, la TASCD también propone interesantes reflexiones. Teniendo en cuenta que las acciones basadas en los juicios contemplan procesos más lentos y reflexivos, el autocontrol y la disuasión desempeñan ahí un importante papel. Además, las entradas del entorno dotadas de una carga moral pueden convertir las acciones o inacciones habituales en acciones deliberativas, en que, como visto, el autocontrol y la disuasión sí pueden incidir.

Siguiendo este raciocinio, ni que decir tiene que la TASCD arroja una potente luz sobre las teorías clásicas del control social, en la medida en que sostiene que el 
autocontrol no es un rasgo de la personalidad de los sujetos, sino un ejercicio, sólo posible cuando se delibera sobre las alternativas de acción, es decir, cuando suceden los juicios morales. Para la TASCD, el autocontrol es, pues, un concepto situacional más que un concepto individual, y es una cuestión de moralidad. Wikström (2006: 546), al afirmar que «una persona ejerce autocontrol cuando actúa de conformidad con su moralidad al hacer frente a motivaciones que impliquen alternativas de acción que entren en conflicto con su moralidad», propone que el autocontrol debe ser comprendido como una "gestión moral con éxito de las respuestas a determinadas motivaciones», lo que es un hallazgo no sólo en términos criminológicos, pero sobre todo político-criminales.

Por fin, en cuanto a la disuasión, la TASCD, del mismo modo, presenta notables aclaraciones: i) la disuasión no funciona cuando la acción es habitual (no hay razonamiento) ni tampoco cuando no existe miedo a las consecuencias (el autor incluso asevera que conceptos como "preocupación» o «ansiedad» son, en realidad, mejores que «miedo» para describir la emoción activa objeto de disuasión); ii) la disuasión tiene la capacidad de romper el hábito, convirtiéndolo en acciones deliberativas, sobre las cuales sí puede influir; iii) aumentar el umbral moral de los sujetos les permite ampliar sus capacidades receptivas hacia las cualidades disuasorias de un entorno, lo que fomenta así el autocontrol; iv) «es probable que la exposición repetida a entornos con fuertes cualidades disuasorias fomente el desarrollo de hábitos de cumplimiento de normas morales, mientras que la exposición repetida a entornos con cualidades disuasorias débiles fomenta el desarrollo de hábitos de infracción de normas morales» (Wikström, 2006: 549).

\section{Descripción del estudio}

A continuación, serán presentados cuatro estudios de campo con menores y jóvenes -e incluso algunos adultos- involucrados con el narcotráfico en Río de Janeiro. Se trabajará solamente con los aspectos más llamativos de cada uno de ellos de cara a hacer posible la confrontación con la TASCD.

Estudio 1: «Trazando caminos en una sociedad violenta: La vida de jóvenes infractores y de sus hermanos no infractores» (Assis, 1999)

Estudio de campo ejecutado entre abril y diciembre de 1997, de tipo cualitativo, en el que fueron entrevistados 92 jóvenes varones, entre infractores de delitos graves que estaban privados de libertad y sus hermanos o primos no infractores, en las ciudades de Río de Janeiro y Recife. Su objetivo fue identificar qué hace que sujetos que han tenido el mismo tipo de crianza y vivido en contextos socioeconómicos muy semejantes sigan por caminos totalmente distintos en cuanto a la opción o no por el crimen. 
Los acusados por tráfico de drogas eran mayoritariamente reincidentes. Todos demostraron orgullo por pertenecer al narcotráfico, excepto el que negó participar en la red. Dijo haber sido arrestado por estar en un lugar de venta de drogas a la hora de la redada y que los policías lo torturaron para que asumiera ser un miembro más de la banda. Los narcotraficantes reincidentes preferían hablar de los homicidios que practicaron, en detrimento de sus actuaciones como preparadores, empaquetadores, transportadores o vendedores de drogas. Es una demostración, según la autora, de que el comercio de estupefacientes en Brasil y la violencia están estrechamente vinculados.

Existe una estructura jerárquica empresarial en el narcotráfico: variados puestos de trabajo, sueldos diferenciados por tipo de actividad, jornadas laborales definidas, reglas y cumplimiento de órdenes, e incluso un sistema comisionado para vendedores, gerentes y subgerentes. La meta de los entrevistados identificados como narcotraficantes era ascender a gerente. La mayoría de ellos informó trabajar para una red distinta a la que actuaba en las favelas donde vivían, para proteger a sus familias y ocultarles su verdadero trabajo. Terminan viviendo en hospederías o en la propia sede de la red para la que trabajan, distanciándose de sus parientes.

Los entrevistados involucrados en el narcotráfico afirmaron no fiarse de nadie. Juzgaban a cualquiera como un potencial delator. Por otra parte, la pertenencia a la red les hacía sentirse poderosos, debido a la mezcla de respeto y miedo que imponían a raíz de la disposición de disparar a matar sin que les temblara el pulso. Actos de crueldad son frecuentes y están legitimados en la subcultura del narcotráfico, aseveraron. Matar es algo banal, la vida no es inquebrantable — ni la propia, menos aún la ajena-, a diferencia de las órdenes recibidas de los de arriba y los ajustes de cuentas, y las torturas son necesarias -incluso antes del padecimiento- para que la imagen del matador impiedoso se mantenga vigorosa en el imaginario.

Por último, la autora ha verificado que las diferencias entre los sujetos infractores y sus hermanos o primos no infractores se debían a:

a) Influencia familiar. Infractores y no infractores demostraron visiones diferenciadas de sus familias: mientras los primeros tendían a mantener imágenes idealizadas de sus progenitores y no reflexivas de los problemas domésticos - como mecanismo subjetivo de defensa-, los segundos han logrado representaciones no idealizadas y desarrollaron conciencia crítica ante los comportamientos familiares dañinos. Así, mientras los primeros reprodujeron los mismos comportamientos violentos de los responsables por sus crianzas, los segundos han conseguido salir del ciclo de autorrepetición, en la medida en que han decidido actuar de modo por completo distinto. En definitiva, lo que para unos fue el veneno, para otros funcionó como antídoto.

b) Influencia social (amigos, comunidad, sociedad). La diferencia más flagrante, según la autora, está relacionada a la elección de las amistades: casi todos los hermanos y primos no infractores han optado por amistades no relacionadas con el mundo 
criminal, comportamiento inverso al de los infractores. También ha verificado que los hermanos y primos no infractores han pasado por más privaciones financieras, lo que les ha hecho considerar que, para salir adelante, tendrían que poner mucho de su parte en sentido de estudiar y trabajar. Los infractores, en cambio, acorde con el relato de sus hermanos y primos, han conseguido disfrutar de mejores condiciones materiales, lo que quizás les ha hecho tener más apego a las ganancias inmediatas.

c) Diferencias individuales. Los hermanos y primos se han descrito como personas más calmadas, más temerosas ante la violencia, más reflexivas ante la vida y más capaces de posponer el logro de beneficios en oposición a los infractores, más valerosos, impulsivos e inmediatistas. El control de la agresividad también ha sido mentado como un elemento diferenciador entre ellos. Otro posible elemento diferenciador se refiere a «tener o no lo que perder»: los hermanos y primos no infractores, al imaginarse cometiendo un delito, piensan en la decepción que causarían a sus familiares y amigos, piensan en el miedo que sentirían de morir o de quedarse heridos, piensan en lo mal que lo pasarían en la cárcel, etcétera. En cambio, a los infractores no les afecta nada de ello.

Estudio 2: «Ni soldados ni inocentes: jóvenes y tráfico de drogas en la ciudad de Río de Janeiro» (Moreira, 2000)

Consiste en un trabajo de campo llevado a cabo entre noviembre de 1998 y noviembre de 1999, con 88 menores en conflicto con la ley penal Río de Janeiro que participaban en el programa «Sistema Aplicado de Protección», por estar involucrados con el narcotráfico. El objetivo del estudio fue analizar la violencia presente en las acciones y contextos de acción de menores narcotraficantes y los posibles impactos de ello en la salud, considerando el perfil de los jóvenes y su grado de participación en el narcotráfico.

La muestra se compuso con adolescentes de edad entre 14 y 19 años, la mayoría del sexo masculino (68) y en la franja etaria de 16 a 18 años (74). Declaraciones de los menores afirman que el narcotráfico prefiere a los sujetos del sexo masculino. La justificación es tienen un carácter más «duro», o sea, mayor disposición para el enfrentamiento y mayor capacidad para resistir a posibles torturas -emprendidas por policías o grupos rivales- sin delatar a los demás.

Asimismo, la mayoría de los sujetos de la muestra eran afrodescendientes (68), además de pertenecer a estratos sociales con pocos recursos económicos. Según el autor del estudio, eso es una evidencia de que negros y pobres son los blancos fáciles del sistema penal, sea por un proceso de etiquetamiento o porque les falta el acceso a los mecanismos de resolución de conflicto de que disponen sus pares en mejor posición en la estructura social. Los menores de las clases sociales abastadas son mayoritariamente blancos, pueden contratar buenos abogados y hasta pueden disponer de 
los medios económicos y políticos para, si eso quieren, practicar corrupción policial y tráfico de influencias.

En lo atinente a la educación, poco más de la mitad de la muestra estaba estudiando (51), aun así, con un déficit de entre 3 y 12 años de estudios perdidos (desfase escolarización-edad). Solamente un joven de 15 años tenía un nivel de aprendizaje un poco más cercano al mínimo establecido por el Ministerio de Educación de Brasil (un año de retraso). Fueron identificados índices elevados de suspensión de cursos escolares; en otras palabras, era demasiado alta la cantidad de veces en las que los menores no fueron considerados aptos a pasar al nivel educacional siguiente.

Sobre el bajo desempeño escolar demostrado por los menores, el autor del estudio aclara que, aparte de las dificultades que enfrentaban en su esfera personal y familiar, la escuela no estaba consiguiendo motivar a los alumnos. Para el autor, el problema de la motivación se debía a: i) la baja inversión en la educación pública; ii) las pésimas condiciones físicas de los establecimientos públicos de enseñanza, su mala localización y número reducido; iii) la baja formación y capacitación de los profesores; iv) los bajos sueldos de los profesionales; v) la desatención hacia los alumnos con problemas de aprendizaje; vi) la baja existencia -incluso inexistencia- y precariedad de bibliotecas y laboratorios; vii) la escasez y precariedad de recursos pedagógicos audiovisuales, sobre todo para apoyar a los alumnos con problemas de aprendizaje.

De cara a lo laboral, casi la totalidad de la muestra informó haber tenido un trabajo formal antes de ingresar en el narcotráfico (81), de los cuales cerca de la mitad lo hizo compaginado con los estudios (44). Varios informaron haber seguido cursos de formación profesional (37), pero sólo uno de ellos dijo haber conseguido un trabajo compatible con lo que había aprendido. Las actividades laborales llevadas a cabo por los menores fueron del tipo que requiere grande o medio esfuerzo físico, baja calificación profesional e intelectual y mal remunerado, como los servicios de limpieza. Una parte de estos menores (22) empezó a traficar con drogas mientras hacían dichas actividades.

En cuanto a las relaciones familiares, para más de la mitad de la muestra ellas se desarrollan en hogares donde viven entre 4 y 7 personas. Las relaciones suelen ser conflictivas y hay casos de violencia física. Las condiciones socioeconómicas en el hogar son precarias y son escasos los momentos agradables en familia. Muchos de los menores que componen la muestra han perdido por completo el vínculo con la figura paterna, mientras que otros ni siquiera han llegado a conocerla.

Cuestionados sobre qué es lo que no les gusta de los lugares donde viven, pese a que hayan sido mencionados problemas sociales, comunitarios y de infraestructura urbana, la mayoría de las respuestas se concentraron en la acción policial en las favelas. En concreto, las contestaciones fueron: las calles sin asfaltar, hechas sólo con barro; la escasa iluminación callejera; la ausencia de teléfonos públicos; el cotilleo entre los vecinos; la desatención social hacia las clases menos favorecidas económi- 
camente; la existencia de sitios donde se abandonan los cuerpos de personas asesinadas; la presencia constante de la policía; las veces en que la policía entra en la favela disparando; las veces en que los policías agreden a los adolescentes; las veces en que la policía invade las casas de los moradores y, al encontrar un muchacho con el pelo teñido, lo arrestan pensando que se trata de un narcotraficante; las veces en que los policías ven algún morador de la favela bien arreglado y con dinero y, por tales características, le pegan por considerar que se trata de un narcotraficante.

Con respecto de los temas de que más les gustaba hablar, no hubo ninguna mención a cuestiones políticas, problemas sociales o cualquier tema relacionado con los obstáculos enfrentados por la colectividad de la que formaban parte. Hubo manifestaciones de preocupación por los problemas familiares, pero, aparte de ello, casi todas las demás respuestas estuvieron relacionadas a trabajo, consumo, diversión, sexualidad, en fin, a la esfera particular de cada uno. En la evaluación del autor, ello demuestra una concepción marcadamente individualista de mundo y una apatía político-social que empeora aún más sus condiciones y la de sus familiares, tornándolos cada vez menos preparados para luchar por sus derechos. En este mismo sentido, en otro momento del estudio, se apuró que sólo 5 de los menores de la muestra habían votado alguna vez y que para 74 de ellos no les interesa la política.

Las motivaciones para el ingreso en el narcotráfico indican el requerimiento de subsanar graves carencias financieras vividas en el seno de las familias, obtener dinero para saciar necesidades variadas de consumo, lograr estatus y poder —incluso para conquistar a las chicas-, ser temido, empuñar armas de fuego y vivir una vida de aventuras, con la adrenalina pulsando en el cuerpo. La influencia de los amigos que ya estaban involucrados ha sido del mismo modo mencionada, además del desempleo asociado a la drogadicción.

A fin de cuentas, el consumo y todos sus accesorios - fama, poder y estatus- es valorado de esta forma por ser una característica distintiva en una sociedad que a diario nos bombardea con su lógica mercantil: vístete con la ropa «A» para ponerte guapo y obtener éxito profesional; bébete la gaseosa «B» para conquistar a las chicas que te gustan; consume la vitamina «C» para lograr una vida más saludable; conduce el coche «D» para sentir la adrenalina fluyendo por tus venas. [...] He el drama: la sociedad de mercado repudia aquéllos que inciden en conductas delictivas, mientras sobrevive, desea, ansía y estimula la multiplicación del dinero que ellos obtienen (Moreira, 2000: 109-112; traducción propia).

El autor subraya que el $52,27 \%$ de los menores de la muestra afirmó haber ingresado en el narcotráfico con el fin de ganar dinero para suplir necesidades y deseos de tenencia de productos no esenciales para la supervivencia. El narcotráfico representa para ellos el único medio para complacerse y solucionar sus problemas más frecuentes. De los 55 menores de la muestra que informaron cuánto recibían por trabajar en 
el narcotráfico, 22 de ellos dijeron ganar un sueldo superior a 195 euros por semana, 15 recibían entre 39 y 78 euros semanales, 4 cobraban entre 117 y 156 euros por semana y 1 de ellos ganaba una paga de 39 euros por semana. El salario mínimo en Brasil a la época del estudio equivalía a cerca de 53 euros al mes. Eso significa que el $40 \%$ de los que aceptaron revelar sus ganancias al investigador cobraban al mes 14 veces el valor de un sueldo base brasileño. Ello seguramente superaba con creces el salario que sus familiares recibían en el mercado laboral lícito.

Son dramáticos los cambios experimentados por los menores en sus vidas personales a raíz de trabajar en el narcotráfico, con graves consecuencias en la salud y constante riesgo de muerte. Sus actividades los someten a intensas y muy frecuentes sensaciones de estrés, ansiedad, nerviosismo, peligro y miedo, dada la imperiosa necesidad de que estén siempre listos para el enfrentamiento armado contra la policía y las facciones rivales. Por ello, pasan a ser dominados por un sentimiento constante de estar siendo perseguidos y se instaura una desconfianza generalizada. Los vínculos de amistad se debilitan enormemente, puesto que, además de las amenazas externas a la red de narcotráfico a la que pertenecen, hay también amenazas internas, representadas por traiciones justificadas por la ambición por un puesto más importante y mejor remunerado. Muchos de estos menores ven a sus compañeros morir delante de ellos con frecuencia. Otros son obligados por sus superiores a matar y torturar a las personas que no hayan cumplido sus acuerdos con el narcotráfico (impago de la mercancía, por ejemplo) o que estén bajo sospecha de ser un infiltrado de la policía o de facciones rivales.

Estudio 3: «Chicos y lobos: Trayectorias de salida del tráfico en la ciudad de Río de Janeiro» (Pereira, 2008)

Sobre la base de un esquema de trabajo cualitativo, llevado a cabo por medio de entrevistas abiertas, esta tesis evalúa la trayectoria de 32 individuos que actuaron en la red de tráfico de drogas y armas ilícitas en Río de Janeiro entre las décadas de 1970 a 1990. Los participantes del estudio son 26 hombres y 6 mujeres que, tras haber pasado por el sistema penitenciario, han dejado de traficar.

El estudio utiliza el concepto de «ethos guerrero» para poder pensar sobre la formación del imaginario de grupos sociales bajo la influencia de la ideología individualista típica de las sociedades posmodernas, que inviabiliza la cohesión social y la estructuración de un sentido de comunidad y cooperación. Dicho concepto, de autoría de Nobert Elias, adviene de la idea de un ethos de la masculinidad que «engloba comportamientos masculinos asentados en el uso de la violencia como recurso a la obtención de ganancias dentro de cuadrillas y modo de imponerse como vencedor de cara al grupo» (Pereira, 2008: 37; traducción propia). Así las cosas, el ethos guerrero se refiere a un estilo de producción de hipermasculinidades desencadenante de 
un habitus asociado a comportamientos recurrentes de competencia brutal entre los individuos, que estimula la necesidad de vencer infligiendo dolor físico para que no sólo se supere al contrincante, sino que igual lo destruya física o moralmente.

Se ve en el estudio que, bajo determinadas condiciones, puede resultar asaz tentadora - en especial cuando se es muy joven - la posibilidad de formar parte de una red de relaciones que proporcione ganancias materiales y simbólicas, aunque el precio a pagar sea vivir en medio de prácticas de violencia cruda y sometimiento cruel. Existir como un paria social, cargar con un pasado doloroso y, a la vez, no disponer de mayores expectativas hacia el presente y el futuro hace que algunos muchachos que viven en favelas, antojando obtener visibilidad y respeto, se sientan seducidos no sólo por la tenencia de armas y el dinero rápido que el narcotráfico les ofrece, pero sobre todo por encarnar el papel del malo, un tipo despiadado y peligroso al que todos temen.

Ni monstruos perversos, ni héroes de un sistema injusto o víctimas del capitalismo salvaje. Acorde con el autor del estudio, además de proporcionar poder y dinero, el narcotráfico suple la necesidad de pertenencia a un grupo con unidad interna consolidada e identidad social claramente definida, en que existe reciprocidad y reconocimiento mutuo entre los miembros. Más allá de tratarse de una búsqueda intrínsecamente humana, tal necesidad es en particular intensa en la juventud. Sucede que la unidad, la identidad y los demás componentes que otorgan sentido grupal en general, sobre todo entre narcotraficantes, son asegurados por la violencia brutal y la disposición para perpetrar la aniquilación — real y también alegórica- de los que pongan en jaque la supremacía individual o colectiva:

El jefe no sólo debe ostentar una «disposición para matar», sino que debe ofrecer demostraciones inequívocas que convenzan a sus secuaces. Estas demonstraciones son ofrecidas en el día a día del narcotráfico. De otra manera, el jefe no será reconocido como un buen líder (Pereira, 2008: 97; traducción propia).

Uno de los participantes del estudio relató que al ser traicionado por un miembro de su banda - lo que en consecuencia le hizo perder la gerencia de su territorio de venta de drogas-, una vez recuperado lo que le había sido expropiado, ordenó la captura del que le traicionó, con el propósito de matarle. Sin embargo, antes de hacerlo, le arrancó la mano con un cuchillo, con tal de hacerle experimentar un dolor intenso antes de morir. Acto seguido, tras haberle asesinado, quemó su cuerpo en un contenedor de basura no sólo delante de su red de narcotraficantes, pero también de sus convecinos. Al terminar el relato, el entrevistado justificó su actitud diciendo que tenía que hacerlo todo tal y como lo hizo para no perder su prestigio frente a los demás.

El autor concluye que se confirma la hipótesis de que efectivamente el universo del narcotráfico se rige por el ethos guerrero. Destaca, asimismo, que haber estado en 
prisión y haber resistido a ello (soportando la privación de libertad y el repulsivo ambiente carcelario, reaccionando a las provocaciones de los detenidos, enfrentándose a los agentes penitenciarios, involucrándose en rebeliones, etcétera) es otro importante elemento en la construcción del «currículo» de los «hombres duros», una especie de prueba de fuego que una vez superada con creces les proporciona notoriedad, autoridad, reconocimiento y ascensión dentro del narcotráfico.

\section{Estudio 4: «Los dos lados de una tragedia carioca:}

La versión de los bandidos» (Junior, 2009)

Se trata de un documental de más o menos 23 minutos de duración sobre la visión de seis narcotraficantes sobre la violencia urbana carioca. Está estructurado a partir de entrevistas hechas in situ en algunas favelas cariocas, sin compromiso académico o científico. Parece ser que las entrevistas seguían un cierto guion, ya que muchas de las preguntas se repetían. Otras, sin embargo, surgieron en forma espontánea. Es probable que, por motivos de edición, no hayan sido exhibidas todas las tomas. Eso impide comparar las respuestas y hacer generalizaciones. No obstante, lo interesante de este material es que, a diferencia de lo que suele suceder en estudios académicos sobre el narcotráfico, los entrevistados no estaban en la cárcel, sino en sus contextos de actuación.

El entrevistador, José Junior, es un ex morador de favela que ha creado una ONG dedicada a sacar personas del crimen. Empieza el documental informando que la ciudad de Río de Janeiro disponía en el momento del rodaje (año 2009) de cerca de 1.020 favelas y que la gran mayoría de ellas estaba bajo el dominio del narcotráfico. Los entrevistados eran todos hombres, en su mayoría afrodescendientes, y presentaban entre 23 y 37 años de edad. La edad informada de ingreso en el narcotráfico varió entre 13014 hasta los 20 años. Cuando eran cuestionados sobre hace cuánto formaban parte del narcotráfico, las respuestas variaron entre 1 y 19 años.

En ningún momento de la entrevista se veía el rostro de los participantes. Muchos de ellos se lo tapaban con un pasamontaña y estaban posicionados de espaldas hacia la cámara. Otros, a su vez, tenían la cámara enfocada hacia sus pies y piernas. Todos tuvieron el sonido de sus voces distorsionadas. Prácticamente todos portaban armas de fuego: revólveres y sobre todo armamento pesado de guerra, como granadas y fusiles 762, AR-15 o AK-47. Uno de los entrevistados llevaba encima un fusil $762 \mathrm{e}$ informó que un arma como la suya valía en el mercado cerca de 25.00o euros. Cuando se le preguntó a otro entrevistado sobre cómo llegaban a las favelas las armas del narcotráfico, la respuesta fue que «hay cosas que no se puede decir», porque comprometería a mucha gente.

Sobre el grado de escolaridad, uno de los participantes informó haber completado sólo la enseñanza fundamental. En las narrativas de todos ellos se puede observar 
un manejo inadecuado del portugués, en términos de lo que se considera la norma culta, y a ratos se ve algo de dificultad a la hora de expresar las ideas y opiniones que desean transmitir. Cuando son cuestionados sobre si habían tenido un trabajado formal antes de ingresar en el narcotráfico, dos contestaron que sí y uno que no. Los tipos de trabajo ejercidos: limpiador de baños, soldado en el ejército (por ocasión del servicio militar obligatorio) y cargador de mercancía en una empresa de exportación. El que dijo haber trabajado limpiando los baños había sido contratado, en realidad, para arreglar neumáticos. Alegaron haber dejado sus trabajos, ya fuera porque sus contratos eran temporales y habían terminado o porque estaban hartos de hacer labores humillantes.

Las motivaciones para el ingreso el en narcotráfico fueron: poder sentirse «guapo» andando a la moda, obtener éxito con las mujeres, consumir bienes de consumo (moto, oro, ropas, etcétera), alejarse de la familia, sustentar a las familias, desempleo y propuestas de empleo degradantes. Cuando fueron cuestionados sobre si lo que se lograba con el narcotráfico les parecía compensador, dos contestaron que sí y uno dijo que «compensa menos que no compensa, porque no se puede vivir de ello toda la vida». Uno de los entrevistados informó ganar cerca de 435 euros por semana. Tenía un puesto razonablemente bueno en la jerarquía del narcotráfico (gerente), pero dijo no poder especificarlo más ni dar más detalles, porque no podría contarlo todo.

A uno de los entrevistados se le preguntó si en la facción narco a la que pertenecía estaba permitido reclutar niños. El entrevistado contestó que no, ni siquiera los mayores (11 o 12 años), porque consideraba que para trabajar en el narcotráfico en la actualidad era necesario tener buen porte físico, ya que los embates con la policía y las demás facciones (rivales) eran muy violentas, de modo que tener niños trabajando con ellos sería un perjuicio. Sin embargo, dijo que hay otras facciones que sí lo hacen.

A la pregunta sobre quiénes eran los ídolos de los niños de las favelas donde vivían, la respuesta fue: los superhéroes de dibujos animados de lucha y también los narcotraficantes. Contaron que son muy acosados por los niños, que muchos de ellos los tienen como modelo a seguir, porque son los ejemplos más cercanos que tienen. Quizás se referían a ejemplos cercanos de alguien con «superpoderes», que vence todas las batallas, que no teme a nadie, alguien que tiene éxito, que consigue todo lo que quiere.

El entrevistador comentó que cuando estuvo en otras favelas, distintas de aquellas donde sucedieron las entrevistas, pudo observar que muchos niños al jugar al juego de persecución llamado «policía y ladrón», preferían casi siempre ser el ladrón, que peleaban por ello. Al preguntar a los participantes si eso también sucedía en sus comunidades, todos han contestado que sí, que eso era muy común. No obstante, el entrevistador informó que en las favelas en las cuales habían sido implementada una unidad de policía pacificadora, ${ }^{3}$ los niños están empezando a presentar un compor-

3. El proyecto de institución de unidades de policía pacificadora (UPP) en favelas cariocas dominadas 
tamiento diferente a la hora de jugar al «policía y ladrón»: estaban eligiendo ser el policía. En seguida, el entrevistador pidió que los participantes opinaran sobre dicho cambio. La respuesta fue algo así como que los niños suelen tener como modelo los seres triunfadores que les son más cercanos. Cuando fueron cuestionados sobre si animaban a los niños a ingresar en el narcotráfico, contestaron que no, muy al revés, que decían a ellos que vivir del narcotráfico «no llevaba a ningún sitio». Justificaron su actuación diciendo que, de lo contrario, se sentirían traicionando a la comunidad a la que pertenecían.

Uno de los entrevistados comentó que el Gobierno sólo se presenta en las favelas por medio de la seguridad pública y no por medio de los servicios de salud, educación o infraestructura urbana, por ejemplo. Complementó su comentario diciendo que era la opresión dirigida hacia los moradores de las favelas lo que le motivaba formar parte del narcotráfico, enfrentarse a la policía y actuar contra las leyes: canalizaba todo su odio, su sentimiento de venganza - que nombró como «derecho de respuesta»—, contra el «sistema» — representación simbólica de todos y todo aquello que consideraba como responsables directa o indirectamente por la opresión de la que hablaba-. Este mismo entrevistado también comentó que tenía a Che Guevara como su referente: «Él fue un revolucionario y yo me considero un revolucionario en lo que hago».

Siguiendo un raciocinio semejante, otro entrevistado dijo que los niños y adolescentes de las favelas sólo consiguen ver delante de ellos dos posibilidades: o estudiar e intentar construir una vida con mucha dificultad y sacrificio, o tornarse bandido y acceder a los bienes materiales y simbólicos que nunca han tenido y que no conseguirían obtener de otro modo. Argumentó, asimismo, que «la propia sociedad, de tanto machacar a la población, nos convirtió en lo que somos». En este discurso, la «sociedad» representaría las clases con recursos financieros y oportunidades de movilidad social, en cuanto que la «población» sería justo lo contrario, los desposeídos y excluidos.

Cuestionados sobre de qué les gustaría trabajar si pudieran ganarse la vida lejos del narcotráfico, las respuestas de los participantes fueron: «No pienso en ello», «me gusta lo que hago» $\mathrm{y}$ «me incorporaría al Ejército Nacional». Sobre la intención de

por el narcotráfico empezó a ser llevado a cabo por el gobierno provincial aproximadamente desde el año 2009. Consistió en un intento de acabar con el poder local del narcotráfico en las favelas y zonas cercanas, quitándoles armas y drogas e implementando un modelo de policía comunitaria permanente, que solucionara conflictos locales, garantizara la seguridad de la comunidad e impidiera la práctica de actividades irregulares e ilícitas. Se trata de un proyecto muy controvertido, que tuvo fuerza a lo largo de algunos años - en gran medida por la disminución de la sensación de inseguridad ciudadana - hasta que empezó a agonizar. Una de las críticas quizá más fuertes al proyecto tiene que ver con la entrada de la mano punitiva del Estado en las favelas para «solucionar» problemas sociales relacionados con la exclusión. 
dejar el narcotráfico, los entrevistados más jóvenes y con menos tiempo de actividad manifestaron que no la tienen, que sienten orgullo de hacer lo que hacen; en cambio, los más mayores - y que además lo llevan haciendo hace mucho tiempo- sí que la tienen, por querer tener una vida tranquila al lado de sus familias - uno incluso se emocionó al hablar del tema-y por no desear que los hijos sigan sus pasos.

Para finalizar, merecen destaque otros dos puntos mencionados por los entrevistados: i) no es posible que el narcotráfico en Río de Janeiro opere sin armas, puesto que el conflicto en la actualidad se ha vuelto aún más violento que antes; ii) el hecho de que adolescentes y jóvenes estén logrando altos puestos en la jerarquía del narcotráfico incrementa la intensidad y la frecuencia de los conflictos armados, una vez que ellos suelen ser mucho más impulsivos y emocionales en sus respuestas. En efecto, se puede ver con claridad en el documental que son muy distintas las posturas de los mayores en comparación con los más jóvenes: los primeros son conscientes de las dificultades de vivir como un narcotraficante y consideran dejarlo, mientras que los segundos son avasalladores en su modo de actuar y están todavía muy seducidos por este universo.

\section{Resultados}

La motivación para la comisión de un acto delictivo, según Wikström, está compuesta por tentaciones, compromisos y provocaciones. Las tentaciones en el fenómeno estudiado operan en los sujetos que desean obtener rápidamente desde bienes de consumo hasta prestigio y visibilidad, lo que los empuja a participar en el narcotráfico. En las favelas cariocas no les ha faltado oportunidad de hacerlo. De igual modo, no les ha faltado provocaciones para involucrarse en actos violentos, puesto que éstas caracterizan el cuotidiano del narcotráfico carioca, repleto de fricciones por las constantes disputas de poder. Los compromisos, a su vez, son evidentes en los estudios seleccionados para este trabajo, en que varios individuos afirmaron que mataban o torturaban porque tenían que hacerlo, porque formaba parte de su trabajo, porque había sido ordenado por sus superiores o porque tenían que eliminar un supuesto enemigo para garantizar su prestigio en la comunidad, su puesto de trabajo o incluso conservar sus vidas. Todo ello explica también por qué hermanos y primos no infractores no se han visto motivados a ingresar en el narcotráfico, aunque no se les hayan faltado oportunidades y a ratos hayan incluso deseado hacerlo: si en algún momento han estado sensibles a la tentación, lo mismo no ha sucedido con el compromiso y las provocaciones, una vez que siquiera han conseguido pensar en la hipótesis de verse en situación de enfrentamiento violento.

En cuanto a valores morales, el narcotráfico tiene su código propio, una especie de «narcocultura», como ha designado el autor del primer estudio presentado en este 
trabajo. Tras una interpretación cruzada de lo que aquí se ha visto, se puede afirmar que los valores propios de la narcocultura carioca están bajo la égida de un «ethos guerrero». La existencia y preeminencia del hábito en conductas delictivas es visible en los estudios de caso evaluados: parece ser que la mayoría de los actos violentos practicados en el marco del narcotráfico son procesos guiados por un seguimiento cognitivo mínimo, que no implican deliberación o razonamiento. Son desarrollados en entornos o circunstancias familiares, conocidas. Nada más ingresar en el narcotráfico, el individuo abraza los valores morales de esta narcocultura y, de ahí en adelante, ya tiene listo el guion sobre cómo reaccionar ante las fricciones típicas de este contexto. El mecanismo asociativo queda ampliamente demostrado en el proceso de definición de la figura del delator: en potencia, cualquiera puede serlo y, ante la duda, es mejor eliminarlo.

La TASCD recalca que los modelos previos de interacciones con determinados entornos influencian en gran medida los conocimientos y aptitudes, experiencias y moralidad actuales de una persona. Eso allana el terreno hacia el desarrollo de hábitos morales. En los estudios examinados, el historial familiar previo de los jóvenes involucrados en el narcotráfico, así como sus contextos comunitarios, se mostró plagado de signos de violencia. Muchos relataron que desde una edad temprana han sentido fascinación por el universo del narcotráfico, que les era cercano. Quizás identificaban ahí la oportunidad de pasar de oprimido a opresor y, precisamente por ello, no les ha sido difícil interiorizar los códigos de la narcocultura. En cuanto a la moralidad individual - es decir, la capacidad de avergonzarse o sentirse culpable por violar una determinada norma moral-, también este elemento de la TASCD se ha visto reflejado en los estudios de caso. Es más, ha marcado de modo contundente la diferencia entre infractores y no infractores.

Sobre las percepciones morales, se ha podido constatar que los sujetos que persisten en la atmósfera violenta del narcotráfico se identifican con valores morales pautados en un ethos guerrero bastante más que con aquéllos que giran alrededor de una resolución pacífica de los conflictos. En dicha circunstancia, el delito es considerado una alternativa válida de acción, y sobre ello no incidirán ni la disuasión ni el autocontrol. Los hábitos morales también han sido identificados en los estudios considerados para este trabajo. Es clara la carga emocional de las situaciones de violencia vividas por los sujetos involucrados en el narcotráfico, lo que se les acciona el sistema experiencial. Los cambios en los hábitos morales, que explican las salidas de los procesos de delincuencia persistente por la conversión de un hábito en un juicio moral, también han sido verificados en los estudios de caso. En los sujetos que dejaran de manera definitiva el narcotráfico porque se convirtieron a alguna religión, han empezado a actuar el autocontrol y la disuasión. 


\section{Conclusión}

La definición de delito propuesta por la TASCD parece adecuada. Ha servido para evaluar un fenómeno (la involucración en el narcotráfico) que contempla variados tipos de crímenes, como el tráfico de drogas ilícitas, homicidios, porte ilegal de armas, contrabando, lesiones, robos y hurtos, etcétera. Los elementos centrales de la TASCD han podido ser identificados en los estudios de caso presentados en este trabajo, por lo que es posible considerarla una teoría criminológica demostrable, pese a que se haya hecho solamente un primer acercamiento. El análisis de los estudios de caso presentados indica que es correcta la afirmación de Wikström de que las acciones o inacciones intencionales de un sujeto no pueden nunca ser explicadas tan sólo por las condiciones del entorno ni tampoco exclusivamente por las características (genéticas $\mathrm{o}$ adquiridas) y experiencias individuales.

Los postulados de la TASCD han facilitado la comprensión de por qué sujetos creados en un mismo núcleo familiar y en un mismo contexto social pueden tomar caminos antagónicos de cara a la delincuencia, algo difícil de ser aclarado por otras teorías criminológicas. Asimismo, posibilita entender los movimientos de entradas y salidas en una supuesta «carrera criminal». Los mecanismos de situación permiten que el fenómeno delictivo sea observado en su cariz dinámico, cambiante, que se va amoldando a las circunstancias, algo que no tiene forma en sí mismo, pero que la va ganando y mutando mientras sucede en diferentes espacio-tiempos.

La TASCD puede ser una brújula para pensar intervenciones sociales en materia de involucración de la juventud con el narcotráfico. Tiene potencial para orientar sobre en qué elecciones pueden operar la disuasión y el autocontrol y en qué momento de los procesos de acción ello debe suceder. Ofrece pistas para la planificación de intervenciones sociales que incidan sobre las elecciones basadas en el hábito, con tal de fomentar que se conviertan en elecciones racionales. En este sentido, por ejemplo, se ha podido extraer de este estudio preliminar que una forma posible de lidiar con el problema de la involucración de la juventud con el narcotráfico es la estructuración de intervenciones con potencial de repercutir sobre el desmantelamiento del ethos guerrero, las cuales tendrán que actuar en el hábito para lograr la deconstrucción del modelo de masculinidad tóxica.

Para finalizar, es importante registrar las siguientes recomendaciones para trabajos futuros: i) profundizar en las metodologías de análisis más usualmente desarrollados en el test de la TASCD, para poner a prueba sus supuestos y verificar su aplicabilidad de cara a la temática de juventud y narcotráfico América Latina; ii) la elaboración efectiva y sistemática de un estudio metaanalítico que explore en profundidad las posibilidades de interlocución entre la TASCD y el referido objeto de estudio. 


\section{Reconocimiento}

Esta es una versión modificada y traducida al español de un artículo publicado en Brasil en enero de 2013, en portugués, en versión estrictamente impresa y en una revista que hoy se encuentra descatalogada. Se trata del artículo «Juventude, narcotráfico e a teoria da ação situacional da causação do delito", en Revista Ciências Penais (Revista da Associação Brasileira de Professores de Ciências Penais), año 9, volumen 17 (julio-diciembre de 2012), pp. 107-153.

Este estudio ha sido auspiciado por el MAEC-AECID de España.

\section{Referencias}

Assis, Simone (1999). Traçando caminhos em uma sociedade violenta: A vida de jovens infratores e seus irmãos não-infratores. Río de Janeiro: FIOCRUZ/Unesco.

Baratta, Alessandro (2003). «Prefacio». En Vera Malaguti, Difíceis ganhos fáceis: Drogas e juventude pobre no Rio de Janeiro (pp. 15-33). Río de Janeiro: Revan.

Borba, Pedro (2009). «Narcotráfico nas Américas». En Dossiê temático. Volumen 5. Puerto Alegre: UFRGS/NERINT.

DowDNey, Luke (2003). Crianças do tráfico: Um estudo de caso de crianças em violência armada organizada no Rio de Janeiro. Río de Janeiro: Sete Letras.

IPEA, Instituto de Pesquisa Econômica Aplicada (2019). Atlas da violência 2019. Río de Janeiro: IPEA.

Junior, José (2009). «Os dois lados de uma tragédia carioca: A visão dos bandidos». Conexões Urbanas, episodio 2, segunda temporada. Disponible en bit.ly/2Jqm7jQ y bit.ly/3hsnren.

Maíllo, Alfonso (2009). Introducción a la criminología. Madrid: Dykinson.

MaÍllo, Alfonso y Antonio Rojas (2018). "Autocontrol y moralidad individual en la causación del delito: Una prueba de la teoría de la acción situacional». Revista Electrónica de Ciencia Penal y Criminología, 20-23: 1-18. Disponible en https://bit. ly/3aIQRIn.

Mclaughlin, Eugene y John Muncie (2012). Diccionario de criminología. Barcelona: Gedisa.

Moreira, Marcelo (2000). «Nem soldados nem inocentes: Juventude e tráfico de drogas no Rio de Janeiro». Tesis de maestría en Salud Pública, FIOCRUZ, Río de Janeiro.

NaCiones Unidas (2010). Word population prospects: The 2008 revision. Nueva York: Naciones Unidas.

Pereira, Luiz Fernando (2008). Meninos e lobos: Trajetórias de saída no tráfico na cidade do Rio de Janeiro. Río de Janeiro: IMS/UERJ. 
PÉREZ, Rebeca (2007). Seguridad ciudadana y convivencia democrática: El caso BrasilAmérica Latina. Río de Janeiro: Flacso.

Rodríguez, Juan Antonio y Christopher Birkbeck (2017). «La teoría de la acción situacional: Una prueba del proceso de percepción-elección mediante la encuesta factorial en Venezuela». Revista de Derecho Penal y Criminología, 3 (18): 265-304. Disponible en https://bit.ly/3pcOHod.

WAISElfisz, Julio (2011). Mapa da violencia 2011: Os jovens do Brasil. São Paulo: Instituto Sangari.

Wikström, Per-Olof H. (2006). «Personas, entornos y actos delictivos: Los mecanismos de situación y la explicación del delito». En José Luís Guzmán Dálbora y Alfonso Serrano Maíllo (editores), Derecho penal y criminología como fundamentos de la política criminal (pp. 509-551). Madrid: Dykinson.

Wiкström, Per-Olof H., Dietrich Oberwittler, Kyle Treiber y Beth Hardie (2012). Breaking rules: The social and situational dynamics of young people's urban crime. Oxford: China Scholarship Council, Oxford University Press.

\section{Sobre la autora}

Clarissa Pepe Ferreira es doctora «sobresaliente cum laude» en Sicología Social del programa de Doctorado en Investigación e Intervención Social y Comunitaria de la Universidad de Málaga, España, en cotutela con el programa de Doctorado en Sicología Social de la Universidad de São Paulo, Brasil. Experta en Criminología de la Universidad Nacional de Educación a Distancia, España. Magister en Criminalidad e Intervención Social en Menores de la Universidad de Málaga. Experta en seguridad pública y ciudadanía en Flacso Brasil (Río de Janeiro). Licenciada en Ciencias Jurídicas y Sociales (Derecho) de la Universidad Federal de Río de Janeiro, Brasil. Investigadora colaboradora en el laboratorio INCIDIR de la Universidad de São Paulo. Su correo electrónico es clarissapepe@yahoo.com.br. (D) https://orcid. org/0000-0001-7648-1160. 
El Anuario de Derechos Humanos es una publicación semestral de referencia y consulta en materia de derechos humanos y campos afines. Busca ser un espacio de discusión de los temas centrales en el ámbito nacional e internacional sobre derechos humanos. Es publicado desde 2005 por el Centro de Derechos Humanos de la Facultad de Derecho de la Universidad de Chile.

\author{
EDITORA \\ Claudia Iriarte Rivas \\ ciriarter@derecho.uchile.cl \\ SITIO WEB \\ anuariocdh.uchile.cl \\ CORREO ELECTRÓNICO \\ anuario-cdh@derecho.uchile.cl \\ LICENCIA DE ESTE ARTÍCULO \\ Creative Commons Atribución Compartir Igual 4.o Internacional
}

\author{
\% \\ La edición de textos, el diseño editorial \\ y la conversión a formatos electrónicos de este artículo \\ estuvieron a cargo de Tipográfica \\ (www.tipografica.io)
}

